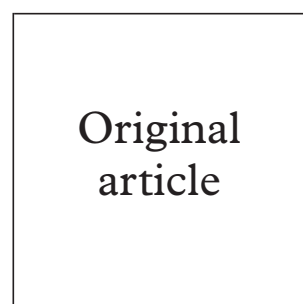

\section{Health issues associated with increasing use of "crack" cocaine among female sex workers in London}

H Ward, A Pallecaros, A Green, S Day
Department of Epidemiology and Public Health, Imperial College School of Medicine, London

H Ward

A Green

S Day

Department of Genitourinary Medicine, St Mary's NHS Trust, London A Pallecaros

Correspondence to: Helen Ward, Department of Epidemiology and Public Health, Imperial College School of Medicine, London W2 1 PG

h.ward@ic.ac.uk

Accepted for publication 20 April 2000

Objectives: To document changes in "crack" cocaine use in the sex industry in London, and to assess health risks associated with the drug.

Design: Two serial cross sectional surveys.

Subjects: Sex workers interviewed in 1989-9 and 1995-6.

Main outcome measures: Self reported use of crack cocaine; clinical history of sexually transmitted infection and pregnancy, clinical outcomes.

Results: The proportion of women reporting crack use increased significantly from 22/193 $(11 \%)$ in $1989-91$ to $48 / 143(34 \%)$ in $1995-6$. Women in all the main prostitution sectors reported crack use. Crack users had been working in prostitution for longer, were more likely to have worked on the streets, to inject drugs, and to have a partner who injected. Crack use was associated with termination of pregnancy and with hepatitis $\mathrm{C}$ infection. The association with hepatitis $\mathrm{C}$ was partially explained by confounding with injecting drug use.

Conclusions: Crack use is more common and less problematic than clinical presentation suggests. Use has increased over the past decade, and is associated with hepatitis $\mathrm{C}$ infection and termination of pregnancy. It is possible that crack use facilitates hepatitis $\mathrm{C}$ transmission due to oral lesions from smoking. Crack use can be difficult to identify because of the stigma of being labelled a "crack whore," therefore information on crack might usefully be integrated into general health promotion material on drugs and safer sex.

(Sex Transm Inf 2000;76:292-293)

Keywords: “crack" cocaine; female sex workers; London

\section{Introduction}

An association between "crack" cocaine (crack) use, commercial sex, and increased risk of HIV infection and syphilis had been reported from North America. ${ }^{12}$ Increasing use of crack in the sex industry has been reported in the United Kingdom and, in a west London project (the Praed Street Project), staff noted an increase in the number of women with unusual health problems apparently associated with crack use, including unwanted pregnancy and sexually transmitted infections (STI). In London we previously reported a low risk of HIV and other sexually transmitted infections in commercial sex. ${ }^{3}$ In this report we document changes in crack use and health risks associated with the drug.

\section{Subjects, methods, and results}

Change in the use of crack over time was determined by combining information from two surveys of sex workers in 1989-91 and 1995-6. The same questions were used in both surveys. Both samples were women recruited through the Praed Street Project clinic. The first sample was part of a larger survey that included women recruited through fieldwork, ${ }^{3}$ but to improve comparability only the clinic sample was included. A history of therapeutic termination of pregnancy and of sexually transmitted infection was based on self report. Data were analysed using sPSs, including stepwise logistic regression.
Twenty two (11.4\%) of 193 women in the first sample reported ever using crack, compared with $48(33.6 \%)$ of 143 in the later sample. Multivariate analysis controlling for injecting drug use and street work showed a significant increase in use between the two surveys (OR 4.81, 95\% CI 2.49, 9.31, $\mathrm{p}<0.0001$ )

In the recent sample only $14(10 \%)$ women reported using crack within the past 3 months; consumption ranged from occasional, recreational to heavy and dependent use. We compared women who had ever used crack with the rest. There were no significant differences in age (median 27 years, range 17-44), ethnicity ( $77 \%$ white), or numbers of sexual partners (paying or non-paying). Crack users had been working longer (see table 1), and in all major prostitution sectors (streets, escort agencies, flats, saunas, privately, and other). They were more likely to have worked on the streets in the past $(13 / 32(41 \%)$ compared with $11 / 67$ (16\%), $\mathrm{p}<0.05$, OR 3.5, 95\% CI 1.3, 9.1), to have injected drugs, to have a partner who injected, and to have used other illicit drugs. Crack users were less likely to report using condoms for all vaginal sex with clients, but this was not statistically significant.

Five women had hepatitis C infection; all reported crack use, and three had injected drugs. Crack use was associated with a past history of STI and therapeutic termination of pregnancy. A logistic regression model was developed for these two variables to control for age (cumulative incidence of STI and termina- 
Table 1 Comparison of crack users and non-crack users

\begin{tabular}{|c|c|c|c|}
\hline & \multicolumn{2}{|c|}{ Ever used crack } & \multirow{2}{*}{$\begin{array}{l}\text { Univariate analysis } p \text { value; } \\
\text { odds ratio ( } 95 \% \text { confidence } \\
\text { interval) }\end{array}$} \\
\hline & $\begin{array}{l}\text { Yes }(\%) \\
(n=48)\end{array}$ & $\begin{array}{l}\text { No }(\%) \\
(n=95)\end{array}$ & \\
\hline $\begin{array}{l}\text { Time in sex work: median years } \\
\text { (range) }\end{array}$ & $4(1-13)$ & $2(0-21)$ & $<0.05$ (Mann-Whitney U) \\
\hline Age: median years (range) & $28(19-42)$ & $27(17-44)$ & \\
\hline Injecting drug use (ever) & $8 / 42(19)$ & $2 / 76(3)$ & $<0.01$; OR $8.71(1.8,43.2)$ \\
\hline Sex with injecting drug user & $10 / 41(24)$ & $6 / 86(7)$ & $<0.01 ;$ OR $4.3(1.4,12.8)$ \\
\hline \multicolumn{4}{|l|}{ Condom use (clients) ${ }^{\star}$} \\
\hline Vaginal sex & $36 / 39(92)$ & $76 / 76(100)$ & \\
\hline Oral sex & $23 / 32(72)$ & $57 / 73(78)$ & \\
\hline Past sexually transmitted infection $\dagger$ & $30 / 46(65)$ & $40 / 90(44)$ & $<0.05 ;$ OR $2.3(1.1,4.9)$ \\
\hline Past termination of pregnancy & $19 / 30(63)$ & $18 / 62(29)$ & $<0.01 ;$ OR $4.0(1.6,10.1)$ \\
\hline Hepatitis C $S$ & $5 / 32(16)$ & $0 / 58$ & $<0.01 ;$ OR $3.23(2.4,4.4)$ \\
\hline Hepatitis B & $2 / 28(7)$ & $1 / 58(2)$ & \\
\hline
\end{tabular}

${ }^{\star}$ Number of women reporting condom use with all clients for that type of sex in the previous month.

†Sexually transmitted infection included one or more of: gonorrhoea, chlamydia, genital herpes, trichomoniasis, genital warts, syphilis.

\Serological evidence of $\mathrm{HCV}$ infection.

ๆSerological evidence of past hepatitis B infection.

tion increase with age), duration of prostitution, and the interaction between these two factors. Crack use remained significantly associated with termination of pregnancy (odds ratio $4.52,95 \%$ CI $1.45,14.13, \mathrm{p}=0.009$ ) but not with past STI (odds ratio $1.62,95 \%$ CI $0.55,4.76, \mathrm{p}=0.377)$.

\section{Discussion}

The initial observation motivating this studynamely, the identification of unmet and urgent health needs in crack users, was only partially confirmed. Crack use was more common and less problematic than clinical presentation had suggested. It has increased over the past decade, and is associated with hepatitis C, STI, and termination of pregnancy. These associations can be explained largely by confounding with age/years in prostitution and injecting drug use.

It is possible that crack use facilitates hepatitis $\mathrm{C}$ transmission, as suggested for HIV infection, due to oral lesions from smoking. ${ }^{4}$ In addition, increased risk of STI and pregnancy may result from unsafe sex that we could not identify from cross sectional data. Fieldwork showed that condoms were not used consistently with clients who were seen as "smoking partners".

Whether crack is a cause of health problems or simply a marker of other risks, it may be a useful indicator of particular health needs. Individual use can be difficult to identify because of the stigma of being labelled a "crack whore," therefore information on crack use might most usefully be integrated into general health promotion material on drugs and safer sex.

Funding: This work was supported by the Medical Research Council, and by the NHS Executive (North Thames).

Conflict of interest: none

Thanks to Praed Street Project staff and to participants.

1 Sterk C. Cocaine use and HIV seropositivity. Lancet 1988;ii: 1052 .

2 Edlin BR, Kathleen MD, Irwin L, et al. Intersecting epidemics-crack cocaine use and HIV infection among inter-city young adults. $N$ Engl F Med 1994;331:1422-7.

3 Ward, H, Day S, Mezzone J, et al. Prostitution and risk of HIV: female prostitutes in London. BMF 1993:307:356-8.

4 Faruque S, Edlin BR, McCoy CB, et al. Crack cocaine smoking and oral sores in three inner city neighbourhoods. f Acquir Immune Defic Syndr Hum Retrovirol 1996;13:8792.

5 Green A, Day S, Ward H. Crack cocaine and prostitution in London in the 1990s. Sociol Health and Illness 2000;22:2739. 